\title{
Analytical System for the Analysis of Ferrovanadium Using Spark Ablation Coupled With Inductively Coupled Plasma Atomic Emission Spectrometry*
}

\author{
Aurora Gómez Coedo, Teresa Dorado López, Isabel Gutierrez Cobo and Esther Escudero Baquero \\ Centro Nacional Investigaciones Metalúrgicas (CENIM) Gregorio de Amo 8, 28040 Madrid, Spain
}

\begin{abstract}
Spark ablation coupled with excitation in an argon inductively coupled plasma is applied to the analysis of remelted ferrovanadium. A medium-voltage spark at a high-repetition rate was used as the sampling technique for samples prepared using a high-frequency remelting system. Problems of sample fracturing were avoided by dilution of the ferroalloy with pure iron. Calibration graphs were obtained with samples prepared from a commercial ferrovanadium alloy, previously analysed using standard wet chemical methods and diluted with pure iron at two different dilution ratios. The two $\mathrm{FeV}$ to $\mathrm{Fe}$ dilution ratios were selected in order to cover the desired range of concentrations. When using an $\mathrm{Fe}$ line as the internal standard, the relative standard deviations for the major element (V) are below $0.3 \%$ (V content, 35-80\%). The limits of determination for the minor elements ( $\mathrm{Mn}, \mathrm{Cu}, \mathrm{Al}$ and $\mathrm{Si}$ ) are below the required ISO specifications. The accuracy of the developed method was tested by the analysis of three reference materials.
\end{abstract}

Keywords: Spark ablation; inductively coupled plasma atomic emission spectrometry; ferrovanadium

During the refining stage in steel production, the molten metal composition is adjusted by adding specific elements, which are necessary to give the steel special properties and characteristics of the desired alloy.

Such elements are, generally, incorporated in liquid steel in the form of ferroalloys. Consequently, there is a need to characterize them just before the addition, so that the steel worker can control the casting in the right way. This aspect is important not only from an economic point of view but also from a logistic one. Among these ferroalloys, ferrovanadium is used for $\mathrm{V}$ addition, in order to inhibit austenitic grain growth, to increase hardness and to improve the strength of low carbon steels. These additions may also introduce a host of other elements at low levels. Considering the market trend for 'ultra clean steels', these low residual elements must be kept to a minimum, which is why both major and minor elements must be considered in the analysis of a ferroalloy. ${ }^{1}$

Instrumental methods are now part of the normal routine procedures in industrial laboratories. With such methods, in many instances, it is possible to achieve high precision and even better accuracies than those obtainable with normal wet chemical analysis. Industrial ferroalloys are not suitable for analysis by instrumental methods, because of their physical presentation and so preliminary sample manipulation is necessary. For this reason the term 'analytical system' is used as this incorporates any operation necessary to define the problem completely, from the sample preparation to the analysis.

Sample preparation for the analysis of ferroalloys is conditioned by the analytical technique to be employed. When wet methods are used, it is necessary to apply laborious procedures to achieve quantitative dissolution of the sample. To prepare large amounts of samples for certain instrumental techniques, the three following procedures are generally employed: obtaining metal samples by remelting, as described by Loose et $a l^{2}$ and by Grimaldi et al.; ${ }^{3}$ obtaining pellets by direct powder compaction, according to a study presented by Ambrose; ${ }^{4}$ and obtaining beads from pre-oxidized materials, as described by Staats $^{5}$ and by Petin et al. 6

Obtaining metal samples by remelting of the ferroalloy

\footnotetext{
*Presented at the XXVII Colloquium Spectroscopicum Internationale (CSI), Bergen, Norway, June 9-14, 1991.
}

diluted with iron, in a high-frequency furnace and centrifugation of the melting bath, is a very simple and effective system for obtaining test samples of ferroalloys to be analysed by instrumental techniques.

Inductively coupled plasma atomic emission spectrometry (ICP-AES) is a routine analytical technique for analysing samples after their dissolution. To avoid the laborious dissolution step, many attempts have been made to produce aerosols directly from solid samples and to excite them in the ICP. Human et al. ${ }^{7}$ showed that spark erosion can be used for the production of aerosols from compact metal samples and their subsequent direct analysis by ICP-AES. Lemarchand et al. ${ }^{\mathbf{8}}$ described a spark ablation system for routine operation which can be combined, as a plug-in unit, with the ICP instrumentation. They applied this to the analysis of ferrous alloys.

In the present study, spark ablation coupled with excitation in an argon ICP is applied to the analysis of ferrovanadium from remelted metal samples.

A medium-voltage spark at a repetition rate of 400 sparks per second and a ceramic spark chamber was used for the aerosol production. Calibration samples were prepared from a commercial ferrovanadium, employing two different $\mathrm{FeV}$ to $\mathrm{Fe}$ dilution ratios. These two dilution ratios were selected according to the grade of the commercial ferroalloy, in order to cover the International Organization for Standardization (ISO) analytical specifications for ferrovanadium.

The intensity versus time profiles of the elements studied show the stability of spark erosion and of the aerosol excitation, at least over a period of $75 \mathrm{~s}$. This time is sufficient to determine the five elements of interest in the same analytical programme, using a sequential spectrometer. By making one measurement per element, with an integration time of $0.5 \mathrm{~s}$ per point, and measuring seven points per peak, the time employed to measure five elements in each one of the samples is about $60 \mathrm{~s}$.

Reproducibility and precision tests show that for the determination of the major element $(\mathrm{V})$, the relative standard deviations (RSDs) are below $0.3 \%$ when an Fe line is used as the internal standard ( $\mathrm{V}$ content, 35-80\%). Considering the minor elements $(\mathrm{Mn}, \mathrm{Si}, \mathrm{Al}$ and $\mathrm{Cu})$, the limits of determination achieved are below those required in the corresponding ISO specifications. Accuracy was checked by the analysis of ferrovanadium reference materials. 


\begin{tabular}{|c|c|}
\hline \multicolumn{2}{|c|}{ Inductively heated furnace - Phillips PV 8910} \\
\hline $\begin{array}{l}\text { Power supply } \\
\text { Maximum power h.f. } \\
\text { Frequency } \\
\text { Centrifugal rotating speed } \\
\text { Inert gas } \\
\text { Refractory crucible }\end{array}$ & $\begin{array}{l}220 \mathrm{~V} ; 50 \mathrm{~Hz} \text {; three phase } \\
2.8 \mathrm{~kW} \\
1.2 \mathrm{MHz} \\
450 \mathrm{rev} \mathrm{min}-1 \\
\mathrm{Argon}^{-1} 20 \mathrm{~min}^{-1} \\
\mathrm{SiO}_{2} 15 \%-\mathrm{Al}_{2} \mathrm{O}_{3} 85 \%\end{array}$ \\
\hline Sparking unit- & Jobin-Yvon SAS \\
\hline Sparking chamber & $\begin{array}{l}\text { Ceramic body (the argon transport } \\
\text { gas enters parallel to the sample } \\
\text { surface) }\end{array}$ \\
\hline $\begin{array}{l}\text { Cathode } \\
\text { Generator }\end{array}$ & $\begin{array}{l}\text { Tungsten rod (diameter } 2 \mathrm{~mm} \text { ) } \\
500 \mathrm{~Hz} \text {; maximum repetition rate, } \\
400 \mathrm{~s}^{-1}\end{array}$ \\
\hline ICP spectrometer- & Jobin-Yvon 24 \\
\hline $\begin{array}{l}\text { Generator } \\
\text { Main monochromator }\end{array}$ & $\begin{array}{l}40.68 \mathrm{MHz} ; 1500 \mathrm{~W} \\
0.64 \mathrm{~m}^{\mathrm{C} z e r n y}-\mathrm{Turner} ; \text { grating, } \\
3600 \text { lines } \mathrm{mm}^{-1} \text {; practical } \\
\text { resolution, } 0.013 \mathrm{~nm}\end{array}$ \\
\hline $\begin{array}{l}\text { Reference } \\
\text { monochromator }\end{array}$ & $\begin{array}{l}0.20 \mathrm{~m} \text { focal length; } \\
\text { grating, } 1200 \text { lines } \mathrm{mm}^{-1} \text {; } \\
\text { bandpass of } 2 \mathrm{~nm}\end{array}$ \\
\hline Computer & IBM, 640 Kbytes RAM \\
\hline
\end{tabular}

\section{Experimental}

\section{Instrumentation}

Details of the instrumentation used are given in Table 1.

\section{Remelted Metal Samples Preparation}

Remelted metal samples were obtained from the ferroalloy diluted with pure $\mathrm{Fe}$ with an appropriate dilution ratio. Samples were melted using silica-alumina refractory crucibles (with an approximate capacity of $20 \mathrm{ml}$ ) in an inductively heated furnace. The molten metal obtained was centrifuged in a $94 \% \mathrm{Cu}-6 \% \mathrm{Be}$ mould, which ensured rapid solidification, owing to the higher thermal conductivity of the mould. The cylindrical shaped samples, with a diameter of $32 \mathrm{~mm}$ and a mass of $40 \mathrm{~g}$, were polished by a grinding machine and finished with an abrasive paper disc.

With regard to the instrumental analysis, the dilution ratios employed are critical parameters. These dilution ratios have to be selected to obtain, on the one hand, relatively homogeneous structures covering a wide concentration range, which are free from physical defects and suitable for etching and polishing and, on the other hand, a high degree of accuracy in the ferroalloy analysis. These objectives can be achieved by determining accurately

Table 2 Chemical composition of FeV-C

\begin{tabular}{|c|c|c|c|c|}
\hline \multirow[b]{2}{*}{ Elemen } & \multicolumn{3}{|c|}{$X(\min )-X(\max )$} & \multirow{2}{*}{$\begin{array}{l}\text { Analytical } \\
\text { method }\end{array}$} \\
\hline & $\bar{X}(\%)$ & $(\%)$ & $\mathrm{SD}^{*}(\%)$ & \\
\hline $\mathrm{V}$ & 78.01 & $\begin{array}{l}77.81-78.22 \\
77.85-78.03\end{array}$ & $\begin{array}{l}0.195 \\
0.096\end{array}$ & $\begin{array}{l}\text { Volumetric }\left(\mathrm{Fe}^{\mathrm{II}}\right) \\
\text { ICP-AES }\end{array}$ \\
\hline $\mathrm{Si}$ & 1.70 & $1.66-1.74$ & 0.052 & Gravimetric \\
\hline Al & 0.673 & $0.655-0.698$ & 0.022 & ICP-AES \\
\hline $\mathbf{P}$ & 0.020 & $0.018-0.021$ & 0.003 & Spectrophotometric \\
\hline $\mathrm{C}$ & 0.230 & $0.225-0.232$ & 0.008 & Combustion-IR† \\
\hline S & 0.045 & $0.041-0.050$ & 0.003 & Combustion-IR \\
\hline $\mathrm{Cu}$ & 0.352 & $0.341-0.365$ & 0.018 & AAS $\ddagger$ \\
\hline $\mathrm{Mn}$ & 0.160 & $0.158-0.165$ & 0.006 & AAS \\
\hline$\ddagger \mathrm{AA}$ & & $\begin{array}{l}\text { ation. } \\
\text { ption spe }\end{array}$ & etry. & \\
\hline
\end{tabular}

the melting and centrifugation temperatures of the melting bath. The choice of the FeV to Fe dilution ratio is subject to two restrictions: firstly, accurately known element concentrations in the solid sample, in order to reduce the total analysis error; and secondly, obtaining a solid that is homogeneous in structure and is mechanically sound.

The Fe used to dilute the ferroalloys, in order to obtain mechanically resistent solid samples, has the following composition: $\mathrm{C}=0.0045 \% ; \mathrm{Si}=0.010 \% ; \mathrm{Mn}=0.012 \%$; $\mathrm{P}=<0.005 \%$; and $\mathrm{S}=0.011 \%$. This iron was used in the form of chips, $\approx 1 \mathrm{~mm}$ thick.

Table 2 shows the chemical composition of the commercial ferrovanadium (FeV-C) employed to develop the procedure.

The calibration samples were prepared in the same way as the test samples. Owing to the linear response of the technique, within the concentration levels tested in the studied materials, only two samples were used for calibration. Considering the analytical grade of the commercial ferroalloy used, and the range in which, according to the ISO specifications, the major element can be found in these materials, calibration samples were prepared by remelting two suitable portions of the ferroalloy and pure iron. These samples were used to prepare calibration graphs, which enable the $V$ content of any ferrovanadium sample to be determined, when the test sample is prepared using the optimum dilution ratio.

\section{Spark Ablation Conditions}

The spark ablation conditions are defined by three parameters: $R$ (resistance in ohms), $V$ (voltage in volts) and $f$ (repetition rate in $\mathrm{Hz}$ ). The mildest conditions for spark ablation are obtained with the following parameters $R=2.2 \Omega, V=700 \mathrm{~V}$ and $f=400 \mathrm{~Hz}$. The strongest conditions are obtained with $R=0 \Omega ; V=700 \mathrm{~V}$ and $f=400 \mathrm{~Hz}$.

The parameters that characterize the spark ablation cycle are: source operation (spark conditions); time parameters (pre-scanning, pre-spark, cleaning, transfer and acquisition); argon flow, i.e., permanent flow (which maintains the argon atmosphere) and analytical flow (during the analysis); and valve position (during cleaning and pre-spark functions this is for ejection into the room and during analysis, into the ICP).

The analyte particles are transported into the ICP, through a $0.75 \mathrm{~m}$ long plastic tube (i.d. $5 \mathrm{~mm}$ ), with an argon gas flow of $0.551 \mathrm{~min}^{-1}$.

\section{Results and Discussion}

\section{Preparation of Remelted Samples}

Sample preparation procedures were investigated to select suitable melting parameters (temperatures and times), in order to develop a systematic working method, to provide samples with the following features: a high percentage of recovered material and good structural and chemical homogeneity.

As the process of high frequency furnace melting is easier to control when the material has the same grain size, all the remelted samples were prepared from ferroalloys previously reduced to a grain size of $2-3 \mathrm{~mm}$.

Taking into account the dimensions of the crucibles and the moulds, the total mass of $\mathrm{FeV}+\mathrm{Fe}$ was set at $40 \mathrm{~g}$. In this way, mushroom-shaped samples were obtained, having a head $30 \mathrm{~mm}$ in diameter and with a thickness of $6 \mathrm{~mm}$, and a stem with a diameter of $12 \mathrm{~mm}, 5 \mathrm{~mm}$ high.

Preparation of the remelted samples presents no particular problems when the vanadium content is below $25 \%$. In this way, and considering the ISO specifications for these materials (V content, 35-80\%), the optimum $\mathrm{FeV}$ to $\mathrm{Fe}$ 
Table 3 Composition of low and high calibration samples

\begin{tabular}{cccc}
\multicolumn{2}{c}{$\begin{array}{c}\text { Calibration } \\
\text { sample }\end{array}$} & $\begin{array}{c}\text { Content in the FeV } \\
\text { Cow } \\
\text { from samples with the } \\
\text { dilution ratio } \\
12+28(\%)\end{array}$ \\
\cline { 2 - 3 } Element & $\begin{array}{c}\text { High } \\
(\%)\end{array}$ & $\begin{array}{c}13+27 \\
(\%)\end{array}$ & \\
$\mathrm{V}$ & & & $32.50-84.50$ \\
$\mathrm{Si}$ & 9.75 & 25.35 & $0.70-1.83$ \\
$\mathrm{AI}$ & 0.21 & 0.55 & $0.28-0.73$ \\
$\mathrm{Cu}$ & 0.084 & 0.22 & $0.14-0.36$ \\
$\mathrm{Mn}$ & 0.044 & 0.11 & $0.066-0.17$ \\
\hline
\end{tabular}

dilution ratio was set at $12+28$, in order to cover all ranges of concentrations.

The calibration samples were prepared taking into account the analytical grade of the commercial ferrovanadium used (FeV-C, $\mathrm{V}=78 \%$ ) and the range of concentrations over which the major element can be found. The low standard was prepared with a dilution ratio of $5+35$ and high standard with a dilution ratio of $13+27$. The over-all recovery of the material was $>99 \%$. Table 3 shows the chemical composition of these two calibration samples for major and minor elements.

The remelted samples were prepared as follows: maximum temperature reached, $1900^{\circ} \mathrm{C}$; time, $125 \mathrm{~s}$; and centrifugation temperature, $1700^{\circ} \mathrm{C}$.

When $\mathrm{Ti}$ and $\mathrm{Al}$ are present, a chemical reaction between the silica-alumina crucible and the liquid contents of the bath can occur (in favour of reduction of the silica to produce silicon contamination in the metal sample). However, as these elements ( $\mathrm{Ti}$ and $\mathrm{Al}$ ) are not incorporated into the metal matrix in a quantitative and homogeneous way in the ferrovanadium samples being considered (the samples contain no $\mathrm{Ti}$ and have only a low $\mathrm{Al}$ content), this phenomena was not observed. The remelted samples obtained are free from physical defects and are suitable for etching and polishing. They show a constant and homgeneous polyhedric structure, according to the corresponding equilibrium diagram. Their chemical homogeneity was confirmed both on and below the surface by spark emission spectrometry. To test the homogeneity on the surface, samples were subjected to four spark discharges at different points. Homogeneity with depth was checked by making cuts parallel to the surface, each $2 \mathrm{~mm}$ thick, and performing four discharges on each one of the new surfaces obtained. This study provided RSD values below $1.5 \%$. These RSD values were calculated from all the spark emission measurements, corresponding to each of the

Table 4 Spark ablation and ICP conditions chosen

\begin{tabular}{|c|c|}
\hline Spark ablation- & \\
\hline Voltage & $700 \mathrm{~V}$ \\
\hline Repetition rate & $400 \mathrm{~s}^{-1}$ \\
\hline Resistance & $\begin{array}{l}\text { Pre-spark, } 0 \Omega \\
\text { Integration, } 2.2 \Omega\end{array}$ \\
\hline Time & $\begin{array}{l}\text { Pre-scanning, } 10 \mathrm{~s} \\
\text { Pre-integration, } 10 \mathrm{~s} \\
\text { Transfer, } 15 \mathrm{~s}\end{array}$ \\
\hline Gas flow & $\begin{array}{l}\text { Permanent carrier gas, } 1.81 \mathrm{~min}^{-1} \\
\text { Analysis carrier gas, } 0.551 \mathrm{~min}^{-1}\end{array}$ \\
\hline Carrier gas pressure & $3 \times 10^{5} \mathrm{~Pa}$ \\
\hline$I C P-$ & \\
\hline Ar gas flow & $\begin{array}{l}\text { Outer, } 141 \mathrm{~min}^{-1} \\
\text { Sheating gas, } 0.41 \mathrm{~min}^{-1}\end{array}$ \\
\hline Power & $1000 \mathrm{~W}$ \\
\hline
\end{tabular}

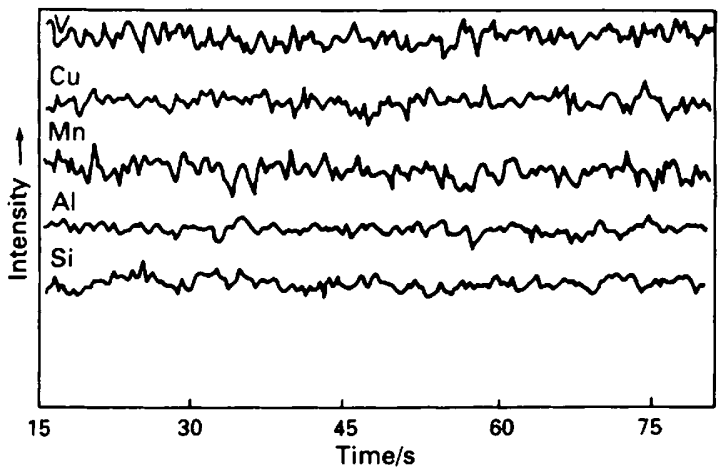

Fig. 1 Intensity versus time profiles

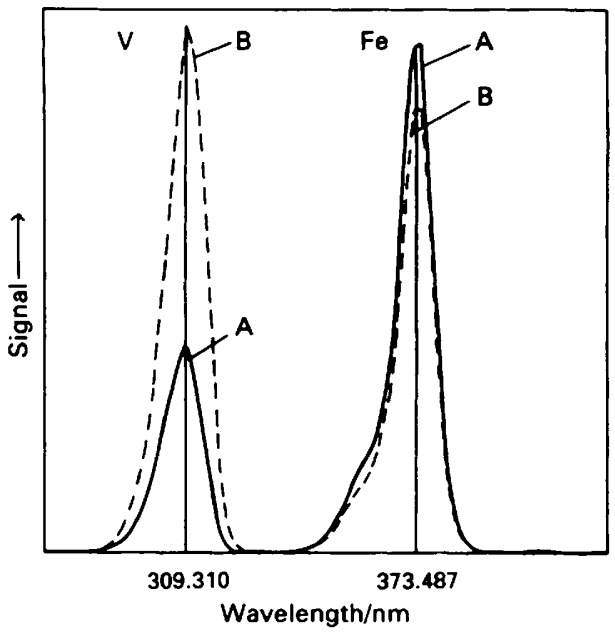

Fig. $2 \mathrm{~V}$ and $\mathrm{Fe}$ scans corresponding to $\mathrm{A}$, low standard $(5 \mathrm{FeV}-\mathrm{C}+35 \mathrm{Fe})$ and $\mathrm{B}$, high standard $(13 \mathrm{FeV}-\mathrm{C}+27 \mathrm{Fe})$

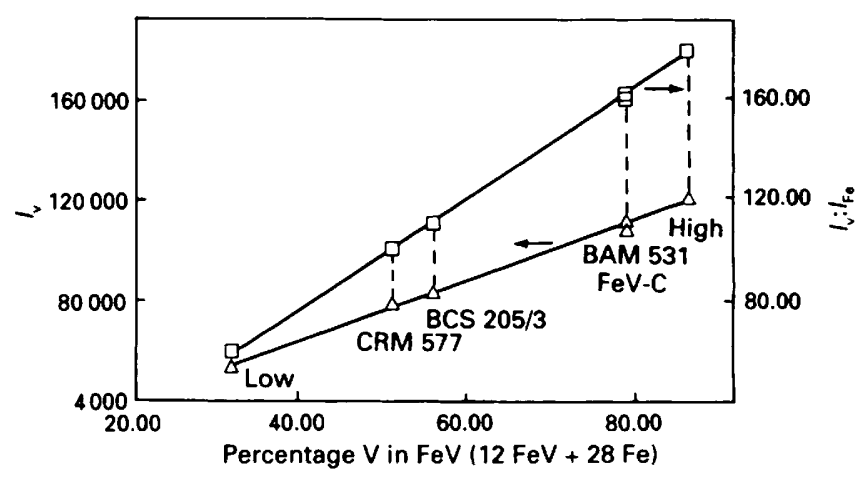

Fig. 3 Determination of $\mathrm{V}$ in $\mathrm{FeV}$

Table 5 Equivalent background concentrations and detection limits for minor elements

$\begin{array}{cccc}\text { Element } & \text { Wavelength/nm } & \text { BEC (\%) } & \text { DL (\%) } \\ \mathrm{Si} & 251.611 & 0.05 & 0.0015 \\ \mathrm{Al} & 396.152 & 0.02 & 0.0005 \\ \mathrm{Cu} & 327.396 & 0.005 & 0.0002 \\ \mathrm{Mn} & 257.610 & 0.03 & 0.0008\end{array}$

elements being considered. To verify the compositions, wet chemical analytical methods were used for all of the elements. A comparison between the percentage of the elements in the initial commercial ferroalloy, and the results obtained in the remelted samples analysed, calculated on the basis of the dilution ratio employed, shows good agreement. 
Table 6 Certified and found values for reference materials

\begin{tabular}{|c|c|c|c|c|c|c|c|c|c|c|}
\hline \multirow{2}{*}{$\begin{array}{l}\text { Reference } \\
\text { material }\end{array}$} & \multicolumn{2}{|c|}{$V(\%)$} & \multicolumn{2}{|c|}{ Si $(\%)$} & \multicolumn{2}{|c|}{$\mathrm{Al}(\%)$} & \multicolumn{2}{|c|}{$\mathrm{Cu}(\%)$} & \multicolumn{2}{|c|}{$\operatorname{Mn}(\%)$} \\
\hline & Certified & Found & Certified & Found & Certified & Found & Certified & Found & Certified & Found \\
\hline $\begin{array}{l}\text { CRM } \\
577-1\end{array}$ & 50.16 & 50.30 & 1.79 & 1.725 & 0.414 & 0.398 & 0.054 & 0.050 & 0.158 & 0.165 \\
\hline $\begin{array}{l}\text { BAM } \\
531-1\end{array}$ & 77.88 & 77.57 & 0.69 & 0.629 & 1.59 & $1.651^{*}$ & 0.019 & 0.017 & 0.15 & 0.138 \\
\hline $\begin{array}{l}\text { BCS } \\
205-3\end{array}$ & 54.9 & 55.08 & 0.54 & 0.523 & - & 0.859 & - & 0.050 & - & 0.185 \\
\hline
\end{tabular}

Under the conditions given in Table 4 , the particles obtained from a 1 min spark-ablation attack, on a $12+28$ $\mathrm{FeV}-\mathrm{C}+\mathrm{Fe}$ remelted sample (with concentrations corresponding to $23.40 \% \mathrm{~V}$ and $75.62 \% \mathrm{Fe}$ ) were trapped and dissolved in dilute $\mathrm{HNO}_{3}+\mathrm{HCl}$. Subsequently the solution was analysed for the major elements ( $\mathrm{V}$ and $\mathrm{Fe}$ ) by ICP-AES and it was found that approximately $2.5 \mu \mathrm{g} \mathrm{min}^{-1}$ of $\mathrm{V}$ and $7.5 \mu \mathrm{g} \mathrm{min}^{-1}$ of Fe reached the ICP.

When performing six spark ablation ICP signal measurements on the same sample, the RSDs of the intensity ratios for $\mathrm{V}$ to $\mathrm{Fe}$ were below $0.5 \%$. The Fe line used as an internal standard was at $373.487 \mathrm{~nm}$.

\section{Selection of Analytical Lines}

In order to select lines for each of the elements being considered, spectral scans of solutions containing approximately the background equivalent concentration (BEC) of the particular element and the maximum expected concentrations of all the others, were taken. The most prominent line for each element was investigated first, and if an interference was found, then the next most prominent line was checked, until an interference-free line was found. After this study of sensitivity and spectral interferences, the analytical lines selected were: V, 309.310; Si, 251.611; Al, 396.152; $\mathrm{Cu}, 327.396$; and $\mathrm{Mn}, 257.610 \mathrm{~nm}$.

Fig. 1 shows the intensity versus time profiles for these elements. The stability of the emissions, over at least $75 \mathrm{~s}$, allows the determination of the five elements of interest in the same analytical programme, using a sequential spectrometer.

Fig. 2 shows scans for $\mathrm{V}$ and $\mathrm{Fe}$, using the spark ablation sampling system, for the two calibration samples.

Calibration graphs for the determination of vanadium, obtained from the two calibration samples (high and low), are given in Fig. 3. These calibration graphs plot both $I_{v}$ versus $c_{\mathrm{v}}$ and the intensity ratios $\left(I_{\mathrm{v}} / I_{\mathrm{Fe}}\right)$ versus $c_{\mathrm{v}}$, where $c$ is concentration. Generally, in a ferrovanadium, when the vanadium content increases, the iron content decreases, producing a higher intensity ratio, which is why the slope of the graph of intensity is greater. The values found for the reference alloy, analysed for a dilution ratio of $12+28$, are inserted into these graphs.

Detection limits for the minor elements were calculated using the following formula:

$$
D L=2 \times S D \text { (background) } \times B E C
$$

The SDs (standard deviations) of the background were measured using AMKO IRON (Wissenschaftlich-technische Instruments, Gatnerweg, Germany) (pure iron, with certified contents for all the elements of interest below 1 ppm). The same AMKO IRON was employed to measure the BECs. Table 5 shows the measured BECs and the calculated DLs.

The accuracy of the developed method was tested by analysing three ferrovanadium reference materials: euronorm certified reference material, ECRM 577-1, Ferrovanadium; Bundesanstalt für Materialforschung und-prüfung, BAM 531-1 Ferro-Alloy; and British Chemical Standard, BCS-CRM 205/3 Ferro-Vanadium. Table 6 shows the certified and found values from remelted samples prepared with the desired optimum dilution ratio $12+28$ ( $\mathrm{FeV}$ to $\mathrm{Fe})$.

\section{Conclusion}

From the results presented it can be concluded that spark ablation is valuable as a direct sampling technique for the analysis of ferrovanadium, remelted samples of which were obtained by fusion of appropriate proportions of ferrovanadium and iron, in an inductively heated furnace. The elemental composition of the aerosol, produced from these remelted metal samples using a high repetition rate spark at medium voltage, matches the bulk composition of the ferroalloy fairly well. The RSD values for $\mathrm{V}$, using an $\mathrm{Fe}$ line as an internal standard, are comparable to those obtained from dissolved samples. Repeatability for a V concentration of between 35 and $80 \%$ (the range considered in ISO specifications) is better than $0.40 \%$. This system of sample preparation also enables the minor elements to be determined, ( $\mathrm{Si}, \mathrm{Al}, \mathrm{Cu}$ and $\mathrm{Mn}$ ) with limits of determination below the required ISO specifications. Preparation of calibration samples from a ferroalloy of the same type enables possible matrix effects to be compensated for.

\section{References}

1 Fitzgerald, F., Proceedings of the 37 th BSC/BISPA Conference, 1984 , p. 9.

2 Loose, W., and Schmitz, L., Hoesch Ber. Forsch. Entwickl. Unserer Werke, 1971, 6(4), 130.

3 Grimaldi, R., Meucci, A., and Randi, G., L'analisi Strumentale Delle Ferrolegue, G. Etas Kom pass., Milano, 1975.

4 Ambrose, A. D., The X-ray Fluorescence Analysis of Iron Ore Sinter. Specimen Preparation, BISRA Open Report, 1970, $\mathrm{MG} / \mathrm{D} / 671$.

5 Staats, G., Arch. Eisenhüttenwes., 1985, 45, 693.

6 Petin, J., Wagner, A., and Bentz, F., Steel Res., 1985, 56, 215.

7 Human, H. G. C., Scott, R. H., Oakes, A. R., and West, C. D., Analyst, 1976, 101, 265.

8 Lemarchand, A., Labarraque, G., Masson, P., and Broekaert, J. A. C., J. Anal. At. Spectrom., 1987, 2, 481.

Paper $1103016 G$ Received June 17, 1991 Accepted September 13, 1991 